\title{
El bien común en la esfera de la teología, la ética y la moral social"
}

\author{
Carlos Justino Novoa Matallana* \\ Santiago Andrés Sierra González ${ }^{* * *}$
}

Recepción: 3 de febrero de 2018 • Aprobación: 11 de marzo de 2018

\section{Resumen}

Este artículo busca explicitar la noción de bien común desde los desarrollos de la ética social como instrumento para el teólogo moral, que intenta establecer la relación entre la fe y la vida pública. En la arena de la discusión pública y de la teología moral, se develan profundas relaciones entre los documentos eclesiales, el Evangelio y las ciencias humanas. Estos diálogos pueden ser puestos al servicio del mundo actual, en una perspectiva ética, de respeto y de construcción de soluciones comunes.

Palabras clave: teología moral, doctrina social de la Iglesia, bien común, dignidad humana, derechos humanos.

* El artículo está inscrito en la línea de investigación Desarrollos de los principios de la Doctrina Social de la Iglesia y del magisterio latinoamericano, del Grupo Pensamiento Social de la Iglesia en el Centro de Formación Teológica de la Pontificia Universidad Javeriana. Citar como: Novoa Matallana, C. J. y Sierra González, S. A. (2018). El bien común en la esfera de la teología, la ética y la moral social. Revista Albertus Magnus, IX(1), 89-108 Doi: https://doi.org/10.15332/ s2011-9771.2018.0001.04

** Pontificia Universidad Javeriana. Bogotá, Colombia. ORCID: https://orcid.org/00000001-5766-4535. Correo electrónico: cnovoa@javeriana.edu.co

P**** Pontificia Universidad Javeriana. Bogotá, Colombia. ORCID: https://orcid.org/00000002-1251-7651. Correo electrónico: s.sierra@javeriana.edu.co 


\title{
The common good in the sphere of theology, ethics and social morality
}

\begin{abstract}
It seeks to explain the notion of the common good, from the development of social ethics as an instrument for the moral theologian, who tries to establish the relationship between faith and public life. In the public discussion of moral theology, are revealed deep relationships between ecclesial documents, the Gospel and the human sciences. These dialogues can be placed at the service of the current world, in an ethical perspective, respect and construction of common solutions.
\end{abstract}

Keywords: moral theology, social doctrine of the Church, common good, human dignity, Human Rights.

\section{O bem comum na esfera da teologia, ética e moralidade social}

\section{Resumo}

Procura explicar a noção de bem comum, a partir do desenvolvimento da ética social como instrumento do teólogo moral, que procura estabelecer a relação entre fé e da vida pública. $\mathrm{Na}$ arena da discussão pública e da teologia moral, se revelam relações profundas entre os documentos eclesiais, o Evangelho e as ciências humanas, estes diálogos podem ser colocados a serviço do mundo atual, numa perspectiva ética, respeito e construção de soluções comuns.

Palavras-chave: teologia moral, doutrina social da Igreja, bem comum, dignidade humana, Direitos Humanos.

\section{Introducción}

El problema más vivo que experimentan hoy en día los cristianos consiste en encontrar la mejor manera para relacionar adecuada y comprometidamente su fe en Jesucristo con la vida moral, de tal forma que se integre la fe con la reflexión moral, talante compartido con la ética misma. Uno de los aportes por tener en cuenta para responder a este problema es la Doctrina Social de la Iglesia (DSI) 
o Enseñanza Social Católica, entendida como una colección de documentos que aplica las creencias católicas a problemas sociales actuales, que incluye las cuestiones económicas en particular.

Como parte de la teología moral, la Enseñanza Social Católica trata de mostrar las implicaciones prácticas del Evangelio, aplicadas a una variedad de cambios económicos, políticos y sociales que afrontan los creyentes de hoy. Estos documentos del magisterio eclesial católico deben ser considerados como parte de la comunicación divina solidaria, salvífica, actuante, actual, dinámica y verdadera, que ofrece profundas discusiones en el ámbito moral, ético y social. De ahí que se haga necesario tomar algunas de las categorías contenidas en dichos textos, para proponer su aplicación en algunos de los contextos específicos de la vida contemporánea para el bien común.

\section{El Compendio de la Doctrina Social de la Iglesia: discernir el marco para el bien común}

En 2005, se publica el Compendio de la Doctrina Social de la Iglesia, el cual brinda un cuadro completo de las líneas fundamentales del corpus doctrinal de la enseñanza social católica,

de manera completa y sistemática, aunque de forma sintética [...] que es fruto de la sabia reflexión del Magisterio y expresión del compromiso constante de la Iglesia, en fidelidad a la gracia de la salvación de Cristo y en amorosa solicitud por el destino de la humanidad. (Pontificio Consejo “Justicia y Paz", 1967, n. 8)

La finalidad del Compendio de la Doctrina Social de la Iglesia es precisa y se encuentra expresada en su introducción de la siguiente manera:

Se presenta como instrumento para el discernimiento moral y pastoral de los complejos acontecimientos que caracterizan a nuestro tiempo; como guía para inspirar, en el ámbito individual y en el colectivo, comportamientos y opciones que permitan mirar al futuro con confianza y esperanza; como subsidio para los fieles en la enseñanza de la moral social. (n. 83)

De la misma forma, complementa que su objetivo es promover un nuevo compromiso capaz de responder a las exigencias de nuestro tiempo y adecuado a las necesidades y a los recursos del hombre, y 
sobre todo al anhelo de valorar, con formas nuevas, la vocación propia de los diversos carismas eclesiales con vistas a la evangelización del ámbito social, porque "todos los miembros [las cursivas son nuestras] de la Iglesia participan de su dimensión secular". (Juan Pablo II, 1996, n. 15)

Además, aclara que

la primera destinataria de la doctrina social es la comunidad eclesial en todos sus miembros, dado que todos tienen que asumir responsabilidades sociales [...] En las tareas de evangelización, es decir, de enseñanza, catequesis y formación, que suscita la Doctrina Social de la Iglesia, está destinada a todo cristiano, según las competencias, los carismas, los oficios y la misión de anuncio propios de cada uno. (Pontificio Consejo “Justicia y Paz", 1967, n. 83)

El Compendio de la Doctrina Social de la Iglesia está enmarcado en el contexto de la Iglesia del mundo de hoy, para, desde la perspectiva de la doctrina social, ser un instrumento serio y riguroso adecuado para realizar el discernimiento - acto cognoscitivo eclesial y comunitario - tan indispensable hoy. El discernimiento cristiano se funda en la lectura de los signos de los tiempos, realizada a la luz de la palabra de Dios y del "corpus" de verdades que el Magisterio ha constituido como doctrina social de la Iglesia, con la finalidad de orientar la praxis comunitaria y personal. Así se llega al centro mismo de la doctrina social de la Iglesia, a su íntima naturaleza de "encuentro del mensaje evangélico y de sus exigencias $[\ldots]$ con los problemas que derivan de la vida de la sociedad. (Congregación para la Doctrina de la Fe, 1986, n. 72)

Para brindar estas orientaciones de manera concreta, el Compendio de la Doctrina Social de la Iglesia se vale de categorías de análisis que le proporcionan al creyente criterios de acción. En este caso, se opta por destacar uno de sus conceptos centrales: el bien común. Será menester su desarrollo conceptual para subrayar sus implicaciones en la vida cotidiana del creyente (Coughlin, 2001, p. 14). En esta línea, es significativo resaltar que la preocupación por la cuestión social de la Iglesia es asunto de toda la catolicidad y no solo de sus clérigos o miembros pertenecientes a la vida consagrada. Todos los católicos debemos empeñarnos en ello y tomar las decisiones pertinentes por medio de esta praxis. Así lo recuerda el papa Montini: 
Frente a situaciones socio-políticas tan diversas en todo el mundo, nos es difícil pronunciar una palabra única, como también proponer una solución con valor universal. No es este nuestro propósito ni tampoco nuestra misión. Incumbe a las comunidades cristianas analizar con objetividad la situación propia de su país, esclarecerla mediante la luz de la palabra inalterable del Evangelio, deducir principios de reflexión, normas de juicio y directrices de acción según las enseñanzas sociales de la Iglesia, tal como han sido elaboradas a lo largo de la historia y especialmente en esta era industrial, a partir de la fecha histórica del mensaje de León XIII sobre "la condición de los obreros", del cual Nos tenemos el honor y el gozo de celebrar hoy el aniversario.

A estas comunidades cristianas toca discernir, con la ayuda del Espíritu Santo, en comunión con los obispos responsables, en diálogo con los demás hermanos cristianos y todos los hombres de buena voluntad, las opciones y los compromisos que conviene asumir para realizar las transformaciones sociales, políticas y económicas que se consideran de urgente necesidad en cada caso. (Pablo VI, 1971, n. 4)

El ejercicio por definir lo que es bueno para todos, el bien común, debe ir acompañado de una invaluable herramienta: el discernimiento (Francisco, 2013c).

\section{El bien común}

Gaudium et spes define el bien común como "el conjunto de condiciones de la vida social que hacen posible a las asociaciones y a cada uno de sus miembros el logro más pleno y más fácil de la propia perfección" (Concilio Vaticano II, 1965, n. 26). Esta noción pone el acento en el desarrollo espiritual, intelectual y cultural de la persona, a través de la participación en la solidaridad con los demás. Sin embargo, como anota Barbieri (2001), este no es el único uso que se hace del bien común, por ejemplo, en el caso de Juan XXIII quien ha dado significados distintos a esta categoría, aunque articulando con el horizonte de la perfección y de la centralidad de la persona. Una primera alusión al concepto de bien común en Juan XXIII (1963) aparece en Pacem in terris:

Está íntimamente ligado a la naturaleza humana. Por ello no se puede mantener su total integridad más que en el supuesto de que, atendiendo a la íntima naturaleza y efectividad del mismo, se tenga siempre en cuenta el concepto de la persona humana. (n. 55) 
Juan XXIII (1961) en Mater et magistra aporta, además, un matiz de subordinación:

Necesariamente sin quebranto alguno del orden moral y del derecho establecido, procurando armonizar sus derechos y sus intereses con los derechos y los intereses de las demás categorías económicas profesionales, y subordinar los unos y los otros a las exigencias del Bien Común. (n. 147)

Por otro lado, en Pacem in terris (1963) indica que

los gobernantes han de orientar sus esfuerzos a que el Bien Común redunde en provecho de todos, sin preferencia alguna por persona o grupo social determinado [...] No se puede permitir en modo alguno que la autoridad civil sirva al interés de unos pocos, porque está constituida para el Bien Común de todos. Sin embargo, razones de justicia y de equidad pueden exigir, a veces, que los hombres de gobierno tengan especial cuidado de los ciudadanos más débiles, que pueden hallarse en condiciones de inferioridad, para defender sus propios derechos y asegurar sus legítimos intereses. (n. 56)

Por lo visto hasta aquí, y siguiendo lo señalado por Zanotti (1985), podemos señalar que Juan XXIII lo largo de sus escritos asume que

el Bien Común de un grupo social es pues el fin común por el cual los integrantes de una sociedad se han constituido y relacionado en ella. Ese Bien Común tiene como característica distintiva el hecho de que por su propia naturaleza es esencialmente participable y comunicable a los integrantes del grupo social. (p. 22)

Esta centralidad de la persona la sigue Juan Pablo II en Redemptor hominis (1979), para quien el bien común manifiesta la prioridad de la ética sobre la técnica, la primacía de la persona sobre las cosas y la superioridad del espíritu sobre la materia. Así las cosas, es todavía más necesario el discernimiento en las decisiones que han de tomarse en las diversas circunstancias a la luz de los valores fundamentales.

No puede pensarse que sea posible sostener otro paradigma cultural y servirse de la técnica como de un mero instrumento, porque hoy el paradigma tecnocrático se ha vuelto tan dominante que es muy difícil prescindir de sus recursos, y más difícil todavía es utilizarlos sin ser dominados por su lógica. Se volvió contracultural elegir un estilo de 
vida con objetivos que puedan ser al menos en parte independientes de la técnica, de sus costos y de su poder globalizador y masificador. De hecho, la técnica tiene una inclinación a buscar que nada quede fuera de su férrea lógica, y "el hombre que posee la técnica sabe que, en el fondo, esta no se dirige ni a la utilidad ni al bienestar, sino al dominio; el dominio, en el sentido más extremo de la palabra". (n. 16)

En esta línea, Francisco en Laudato si” (2015) también dirá que “la capacidad de decisión, la libertad más genuina y el espacio para la creatividad alternativa de los individuos se ven reducidos" (n. 108; cfr. Laudato si' nn. 9, 14, 60, 107, 110, 112, 113). Sin embargo, el que la persona esté en el centro de la comprensión del bien común en cuanto ser social no implica contraposición entre el bien particular y el bien común. Este es un principio básico de la antropología, que explica el ser del hombre en la singularidad del individuo y en la dimensión social de la persona.

El conflicto se presenta en la vida práctica cuando se procura la armonización entre un bien privado (no necesariamente particular) y el bien común (mucho más que un bien grupal). Así, la pertenencia a un club es la adhesión de algunos a unos bienes privados, que no son compartidos por toda la ciudadanía. Esta es la diferencia entre una asociación y la sociedad, en general, donde hay una condición inherente de intersubjetividad y, por tanto, los bienes particulares deben estar orientados a fines comunes para toda la sociedad, pero la sociedad no suplanta la dignidad humana particular (cfr. Hittinger, 2008).

\section{La importancia de bien común: categoría de análisis}

Si bien se ha expresado hasta ahora que la Enseñanza Social Católica está dirigida a los creyentes, también se ha dicho que estos viven en un mundo plural, con diferentes concepciones de la vida y, por tanto, con sistemas de creencias diversos y con personas que no tienen una creencia o no pertenecen a alguna tradición religiosa.

En un escenario en el que la perspectiva católica tiene una presencia activa y las ciencias sociales han mostrado la importancia de la creencia religiosa en la configuración de la sociedad en y el fortalecimiento del tejido social (cfr. Daloz, Parks, Keen \& Keen, 1996), la categoría de bien común se constituye en un puente para que un teólogo moral pueda llevar a cabo un diálogo público en el que hable desde la moral social. Como anota Elsbernd (2005), la ética social incorpora fuentes de las ciencias económicas, políticas, ambientales y sociales, así como de las 
ciencias teológicas, que incluye la espiritualidad. Esto ha hecho que se gane credibilidad y se reconozcan las competencias y la legitimidad de la interlocución, del discurso y del análisis de la ética social.

Pero en este caso se trata de un movimiento de doble vía. Las ciencias sociales se enriquecen de la teología, y viceversa. Al ser la Encarnación el absoluto ético cristiano por excelencia, la sistemática de la fe tiene que dejarse interpelar en profundidad por todos los demás saberes:

Vivan los fieles en muy estrecha unión con los demás hombres de su tiempo y esfuércense por comprender su manera de pensar y de sentir, cuya expresión es la cultura. Compaginen los conocimientos de las nuevas ciencias y doctrinas y de los más recientes descubrimientos con la moral cristiana y con la enseñanza de la doctrina cristiana, para que la cultura religiosa y la rectitud de espíritu vaya en ellos al mismo paso que el conocimiento de las ciencias y de los diarios progresos de la técnica; así se capacitarán para examinar e interpretar todas las cosas con íntegro sentido cristiano. (Gaudium et spes, n. 62)

En un mundo atravesado por crisis profundas, los análisis de la ética y de la moral social hablan de visiones alternativas, utopía, resurrección y comunidad, entre otros. Con ello, proporcionan tomas de conciencia y horizontes de comprensión diferentes, que empujan la dimensión intelectual del ser humano a plantearse sueños, creatividad, proyectos de vida y motivaciones para luchar contra un mundo injusto (cfr. Carroll, 2002).

Precisamente, el estudio comportamental social ha encontrado en la noción de bien común un elemento central para plantearse el desarrollo humano. Elsberd (2005) recuerda a autores como Hollenbach (2002), quien aporta un marco teórico para asumir el bien común desde la perspectiva de los bienes sociales, con el fin de repensar desde la visión católica la pobreza y la globalización. También Cahill (2002) reinterpreta el bien común desde una perspectiva intercultural, para plantear una ética de corte universal.

Así, la noción de bien común, desde los desarrollos de la ética social, le permite al teólogo moral explicitar la relación entre fe y vida pública. Como persona de fe entra en la arena de la discusión pública aportando sus conceptos, reconociéndose testigo del Evangelio puesto al servicio del mundo, en una perspectiva ética de respeto y de construcción de discursos comunes. Salta a la vista la trascendencia de la relación entre la fe cristiana y la vida pública secular, en la cual acaece un enriquecimiento mutuo de capital relevancia. Es en esta óptica en la que se ubica el gran filósofo contemporáneo Jürgen Habermas, quien, declarándose ateo, lleva 
más de veinte años dedicado a la teología, siendo consciente de la importancia de la mencionada relación:

La neutralidad ideológica del Poder Supremo del Estado democrático, la cual garantiza a cada ciudadano libertades éticas iguales, es incompatible con la generalización política de una cosmovisión secular. Los ciudadanos secularizados, en cuanto se presentan en el papel de ciudadanos, no pueden negar ni a los conceptos religiosos del mundo un potencial verdadero, ni negarles a los conciudadanos creyentes el derecho de convertir aportes con idioma religioso en discusiones públicas. Una cultura política liberal puede esperar hasta de los ciudadanos secularizados que participen en los esfuerzos por traducir aportes relevantes del idioma religioso a un idioma públicamente accesible. (Habermas, 2006, p. 19)

\section{El bien común, la ética y la moral social}

Vista la importancia del bien común como categoría para establecer diálogo en la esfera de lo público, por parte de la teología moral, se hace necesario mostrar cómo este concepto es útil para una ética aplicada a asuntos y problemas contemporáneos, que forman parte de la esfera civil. El primero de ellos tiene que ver con los derechos humanos. De hecho, esta es una de las perspectivas que aparece en Gaudium et spes:

La interdependencia, cada vez más estrecha, y su progresiva universalización hacen que el bien común - esto es, el conjunto de condiciones de la vida social que hacen posible a las asociaciones y a cada uno de sus miembros el logro más pleno y más fácil de la propia perfecciónse universalice cada vez más, e implique por ello derechos y obligaciones que miran a todo el género humano. Todo grupo social debe tener en cuenta las necesidades y las legítimas aspiraciones de los demás grupos; más aún, debe tener muy en cuenta el bien común de toda la familia humana. (n. 26)

Al definir el bien común de esta manera, la Iglesia permite ampliar el panorama para llegar a todas las personas, aun a aquellas que no son creyentes. Esto involucra a todos, incluso a los pueblos que no están adscritos a la Iglesia, la oportunidad de trabajar juntos por una sociedad justa. Es una manera de superar 
el sectarismo y de afirmar una comprensión más profunda de la interconexión de la humanidad independiente de su afiliación religiosa. Además, la preocupación por el bien común elimina las fronteras, no solo entre el creyente cristiano y el no creyente, sino también entre las naciones.

Esta comprensión también está alineada con la comprensión de los derechos humanos, los cuales comparten un discurrir similar en el Concilio Vaticano II, por parte de quien fue protagonista: Juan XXIII. En efecto, aquello lo podemos observar con mayor precisión en Pacem in terris, acudiendo a la centralidad de la persona humana respecto del bien general. Allí se afirma que

en toda convivencia humana bien ordenada y provechosa hay que establecer como fundamento el principio de que todo hombre es persona, esto es, naturaleza dotada de inteligencia y de libre albedrío, y que, por tanto, el hombre tiene por sí mismo derechos y deberes, que dimanan inmediatamente y al mismo tiempo de su propia naturaleza. Estos derechos y deberes son, por ello, universales e inviolables y no pueden renunciarse por ningún concepto. (1963, n. 9)

En las dos anteriores citas de la DSI, se observa cómo el bien común incluye los derechos humanos. Es más, tanto el bien general como tales derechos se refieren a necesidades humanas básicas y a bienes morales personales. Las necesidades básicas incluyen los bienes materiales necesarios para el sustento de la vida, tales como alimento, techo y otros requerimientos humanos. Los bienes morales personales se refieren a las capacidades humanas trascendentes relacionadas con las facultades del intelecto y de la voluntad. Para vivir una vida plena, las personas requieren el conocimiento y la libertad. La acción moral, así como la mayoría de los derechos humanos, solo son posibles cuando una persona tiene la capacidad de autodeterminación (cfr. Maina, 2011).

Sin embargo, la Iglesia no entiende los derechos humanos solo desde la perspectiva liberal de garantías de la dignidad humana. Va mucho más allá: los vincula con la solidaridad, la renuncia y el servicio. Así aparece en las enseñanzas de Pablo VI en Octogesima adveniens cuando invita a que "los más favorecidos deben renunciar a algunos de sus derechos para poner con mayor liberalidad sus bienes al servicio de los demás" (n. 23). Así,

el que manda hoy no es el hombre, es el poder y el dinero, el dinero. Vivimos una sociedad con una economía y unas finanzas sin ética, donde la persona no cuenta para nada, es basura. Este es un sistema que mata gente, injusto de raíz, que debemos cambiar, en el cual se halla una minoría absurdamente rica que genera una gran parte de la 
humanidad en las condiciones más abyectas. El hambre es criminal. Toda esta idolización de la riqueza es el estiércol del demonio. (Novoa, 2017; cf. Francisco, 2013a, 2013b, 2014, 2015b)

Para responder adecuadamente a esta responsabilidad de garantizar los derechos de los demás en la búsqueda del bien común, hay que estar atentos al clamor de los otros, los más necesitados, los pueblos que no han alcanzado a hacer valer sus derechos. $Y$ esto no en sentido abstracto, sino en algunas formas específicas. Una de ellas es la solidaridad con todos aquellos más necesitados que, en lenguaje de Pablo VI (1971), es una solidaridad mundial que

debe permitir a todos los pueblos el llegar a ser por sí mismos artífices de su destino [...] Las relaciones internacionales lleven el cuño del mutuo respeto y de la amistad, de la interdependencia en la colaboración y de la promoción común bajo la responsabilidad de cada uno. Los pueblos más jóvenes o más débiles reclaman tener su parte activa en la construcción de un mundo mejor, más respetuoso de los derechos y de la vocación de cada uno. (n. 65)

Incluso, Juan Pablo II (1991) va más allá y sustituye en algunos de sus escritos el término "bien común" por el de "derechos humanos", como en la siguiente cita: Una ayuda importante e incluso decisiva la ha dado la Iglesia, con su compromiso en favor de la defensa y promoción de los derechos del hombre [las cursivas son nuestras]. En ambientes intensamente ideologizados, donde posturas partidistas ofuscaban la conciencia de la común dignidad humana, la Iglesia ha afirmado con sencillez y energía que todo hombre - sean cuales sean sus convicciones personales - lleva dentro de sí la imagen de Dios y, por tanto, merece respeto. En esta afirmación se ha identificado con frecuencia la gran mayoría del pueblo, lo cual ha llevado a buscar formas de lucha y soluciones políticas más respetuosas para con la dignidad de la persona humana. (n. 22)

En últimas, los derechos humanos forman parte integral de la noción de bien común. Así lo expresó Benedicto XVI en la alocución de la Asamblea General de las Naciones Unidas, el 18 de abril de 2008, con motivo del sexagésimo aniversario de la Declaración Universal de los Derechos Humanos:

La vida de la comunidad, tanto en el ámbito interior como en el internacional, muestra claramente cómo el respeto de los derechos y las garantías que se derivan de ellos son las medidas del bien común que 
sirven para valorar la relación entre justicia e injusticia, desarrollo y pobreza, seguridad y conflicto. La promoción de los derechos humanos sigue siendo la estrategia más eficaz para extirpar las desigualdades entre Países y grupos sociales, así como para aumentar la seguridad. Es cierto que las víctimas de la opresión y la desesperación, cuya dignidad humana se ve impunemente violada, pueden ceder fácilmente al impulso de la violencia y convertirse ellas mismas en transgresoras de la paz. Sin embargo, el bien común que los derechos humanos permiten conseguir no puede lograrse simplemente con la aplicación de procedimientos correctos ni tampoco a través de un simple equilibrio entre derechos contrapuestos. La Declaración Universal tiene el mérito de haber permitido confluir en un núcleo fundamental de valores y, por lo tanto, de derechos, a diferentes culturas, expresiones jurídicas y modelos institucionales.

Aun cuando es claro que el bien común es parte integral de los derechos humanos, la labor profética de la Iglesia es recordarlo de manera permanente. Así lo hace el papa Francisco cuando manifiesta su preocupación respecto de que los derechos humanos pueden ser utilizados como justificación de una fuerte defensa de los derechos individuales o de los de unos pocos o, incluso, de los Estados más ricos y poderosos, sin atender a los derechos más apremiantes de las mayorías menos favorecidas (antítesis del bien común). Por esto, es necesario rescatar el papel de la solidaridad, tal y como lo afirma Benedicto XVI (2008):

Respetando la independencia y la cultura de cada nación, hay que recordar siempre que el planeta es de toda la humanidad y para toda la humanidad, y que el solo hecho de haber nacido en un lugar con menores recursos o menor desarrollo no justifica que algunas personas vivan con menor dignidad.

La solidaridad, entonces, es la brújula del bien común. Sin esta, lo que se genera es un mundo que supone que lo más importante es el propio bienestar, sin considerar que los demás carecen de los bienes mínimos para su propia supervivencia. Este punto es ratificado por Francisco en el Encuentro Mundial de Movimientos Populares:

Solidaridad es una palabra que no cae bien siempre, yo diría que algunas veces la hemos transformado en una mala palabra, no se puede decir; pero es una palabra mucho más que algunos actos de generosidad esporádicos. Es pensar y actuar en términos de comunidad, de 
prioridad de vida de todos sobre la apropiación de los bienes por parte de algunos. También es luchar contra las causas estructurales de la pobreza, la desigualdad, la falta de trabajo, la tierra y la vivienda, la negación de los derechos sociales y laborales. (Francisco, 2014)

Así, entonces, mientras en el discurso político se habla del bienestar general (bien para la mayoría, pero no necesariamente para todos), la Iglesia usa la categoría de bien común aportando a la discusión pública la búsqueda y la lucha por la justicia, con una profunda validez, pertinencia y urgencia para todos, pero atendiendo como labor primera a los más necesitados que se ven rezagados en esta obtención.

Allí entran los pobres con su cultura, sus proyectos y sus propias potencialidades. Aun las personas que puedan ser cuestionadas por sus errores tienen algo que aportar que no debe perderse. Es la conjunción de los pueblos que, en el orden universal, conservan su propia peculiaridad; es la totalidad de las personas en una sociedad que busca un bien común que verdaderamente incorpora a todos. (Francisco, 2014)

Pero además del escenario político en cuanto a los derechos humanos, el bien común sirve también para pensar la vida económica. De hecho, en la carta pastoral Economic Justice for All: Pastoral Letter on Catholic Social Teaching and the U.S. Economy (United States Catholic Bishops, 1986), se toma el concepto de bien común como categoría para analizar y juzgar la vida y los sistemas económicos, a través de seis principios: a) toda institución y decisión económica debe ser juzgada a la luz de si protege o vulnera la dignidad humana; b) la dignidad humana solo puede ser protegida en comunidad y desde ahí deben asumirse las decisiones en torno al producto interno bruto, las necesidades básicas insatisfechas, la inflación, etc.; c) todas las personas tienen el derecho a participar en la vida económica de la sociedad; d) todos los ciudadanos tienen obligaciones, especialmente con los pobres; e) los derechos humanos son la condición mínima para la vida en comunidad; y f) la humanidad, como un todo, actuando a través de las instituciones públicas y privadas tiene la responsabilidad moral de promover la dignidad humana y respetar los derechos humanos (cf. Fox, 2009).

Incluso, esta categoría puede aplicarse a la sostenibilidad. En efecto, el bien común implica el cuidado de la creación de Dios y el destino universal de todos los bienes (cf. Morse \& McNamara, 2009). También Benedicto XVI, en su alocución de la jornada por la paz realizada el 1 de enero de 2008, aseveró que el bien general es uno de los conceptos centrales para pensar los asuntos ambientales, 
porque nos refieren a un hogar común y, por tanto, en una justicia ambiental para asumir las responsabilidades con el bienestar de toda la humanidad y, con ello, con la protección de la Creación de Dios.

El papa Francisco enriquece el concepto de justicia ambiental, que considera necesario recurrir también a la categoría de solidaridad. Esta es consecuente con lo que ha venido predicando sobre el bien común, por eso en la Jornada Mundial de la Juventud afirma:

No es, no es la cultura del egoísmo, del individualismo, que muchas veces regula nuestra sociedad, la que construye y lleva a un mundo más habitable; no es ésta, sino la cultura de la solidaridad; la cultura de la solidaridad no es ver en el otro un competidor o un número, sino un hermano. Y todos nosotros somos hermanos. (Francisco, 2013c)

\section{Un marco para garantizar el bien común: el Estado, la Iglesia, el Evangelio}

Además de ser una categoría central para aportar al debate público, el bien común ha sido pensado en la Iglesia desde la perspectiva práctica, buscando concretarlo en alguna instancia. Así, el Compendio de la Doctrina Social de la Iglesia destaca la importancia del Estado en el cuidado y la promoción del bien común de la sociedad, amparado en los fundamentos analizados arriba (n. 188). Esta misma insistencia la mantiene Francisco en su reflexión sobre el desarrollo integral de todos, el velar por el bien común y la necesidad de una voz profética en esta materia:

Sobre la base de los principios de subsidiariedad y solidaridad, y con un gran esfuerzo de diálogo político y creación de consensos, desempeña un papel fundamental, que no puede ser delegado, en la búsqueda del desarrollo integral de todos. (Francisco, 2013a, n. 240)

Este desequilibrio proviene de ideologías que defienden la autonomía absoluta de los mercados y la especulación financiera. De ahí que nieguen el derecho de control de los Estados, encargados de velar por el bien común. (n. 56)

Las reivindicaciones sociales, que tienen que ver con la distribución del ingreso, la inclusión social de los pobres y los derechos humanos, no pueden ser sofocadas con el pretexto de construir un consenso de 
escritorio o una efímera paz para una minoría feliz. La dignidad de la persona humana y el bien común están por encima de la tranquilidad de algunos que no quieren renunciar a sus privilegios. Cuando estos valores se ven afectados, es necesaria una voz profética. (n. 218)

De esta manera, la Iglesia respeta la autonomía del Estado, pero no renuncia a hacer presencia en el mundo ejerciendo su liderazgo profético y su rol como institución en la conversión real de sus miembros y en la formación de una verdadera, ética y moral social, al servicio del bien común.

La Iglesia católica es una institución creíble ante la opinión pública, confiable en lo que respecta al ámbito de la solidaridad y de la preocupación por los más carenciados. En repetidas ocasiones, ha servido de mediadora en favor de la solución de problemas que afectan a la paz, la concordia, la tierra, la defensa de la vida, los derechos humanos y ciudadanos, etc. ¡Y cuánto aportan las escuelas y universidades católicas en todo el mundo! Es muy bueno que así sea. Pero nos cuesta mostrar que, cuando planteamos otras cuestiones que despiertan menor aceptación pública, lo hacemos por fidelidad a las mismas convicciones sobre la dignidad humana y el bien común. (Francisco, 2013a, n. 65)

Y cuando hablamos de Estado y bien común, necesariamente nos vemos abocados a la praxis política que los hace posibles. Por ello, es tan importante no ignorar las responsabilidades de los cristianos respecto de la edificación de la polis. Es menester de todos el trabajo decidido por la cristalización del bien común:

Se ama al prójimo tanto más eficazmente, cuanto más se trabaja por un bien común que responda también a sus necesidades reales. Todo cristiano está llamado a esta caridad, según su vocación y sus posibilidades de incidir en la polis. Ésta es la vía institucional - también política, podríamos decir - de la caridad. (Benedicto XVI, 2009, n. 7)

En igual perspectiva, se halla el papa Francisco al reivindicar la capitalidad del bien común viabilizado por la construcción de la polis:

La política, tan denigrada, es una altísima vocación, es una de las formas más preciosas de la caridad, porque busca el bien común. Tenemos que convencernos de que la caridad no es solo el principio de las micro-relaciones, como en las amistades, la familia, el pequeño grupo, sino también de las macro-relaciones, como las relaciones sociales, económicas y políticas. (Francisco, 2013a, n. 205) 
Así pues, la tarea de los ciudadanos no puede ser otra que trabajar por el bien de todos como una obligación suprema, como un compromiso con los otros. Así también se recoge en Evangelii gaudium: "Recordemos que el ser ciudadano fiel es una virtud y la participación en la vida política es una obligación moral” (n. 220). Desde la óptica del bien común, entonces, la Iglesia interviene en el mundo y en los Estados nacionales sirviendo en la mediación de conflictos, llegando a lugares a los que nadie llega, promoviendo los derechos humanos en sitios en los que es la única institución creíble. En últimas, trabajando por instaurar el Reino de Dios y su justicia, como fundamento de su verdad evangélica: “Con su enseñanza social, la Iglesia quiere anunciar y actualizar el Evangelio en la compleja red de las relaciones sociales" (Pontificio Consejo "Justicia y Paz", 1967, n. 62).

No se trata simplemente de alcanzar al hombre en la sociedad - el hombre como destinatario del anuncio evangélico-, sino de fecundar y fermentar la sociedad misma con el Evangelio (cfr. Concilio Vaticano II, 1965).

La doctrina social tiene de por sí el valor de un instrumento de evangelización: en cuanto tal, anuncia a Dios y su misterio de salvación en Cristo a todo hombre y, por la misma razón, revela al hombre a sí mismo [las cursivas son nuestras]. (Juan Pablo II, 1991, n. 54)

La evangelización también implica un camino de diálogo. Para la Iglesia, en este tiempo hay particularmente tres campos de diálogo en los cuales debe estar presente, para cumplir un servicio a favor del pleno desarrollo del ser humano y procurar el bien común. (Francisco, 2013a, n. 238)

Pero Francisco en este mismo documento va más allá, nos invita a reconocer a los demás y a salir de nosotros mismos, para construir el bien común como respuesta al amor de Dios:

Cuando la predicación es fiel al Evangelio, se manifiesta con claridad la centralidad de algunas verdades y queda claro que la predicación moral cristiana no es una ética estoica, es más que una ascesis, no es una mera filosofía práctica ni un catálogo de pecados y errores. El Evangelio invita ante todo a responder al Dios amante que nos salva, reconociéndolo en los demás y saliendo de nosotros mismos para buscar el bien de todos. ¡Esa invitación en ninguna circunstancia se debe ensombrecer! Todas las virtudes están al servicio de esta respuesta de amor. (n. 39) 
Así, entonces, el concepto de bien común aparece como posibilidad para que la teología moral siga interpelando al mundo desde la ética y moral social, con un mensaje cargado de sentido, desde la Revelación y la experiencia de fe.

\section{Conclusión}

El paradigma del bien común, como todas las formulaciones que constituyen la Enseñanza Social Católica, no pretende ser una ideología. Es una herramienta para el creyente, que se enfrenta seriamente con las realidades y estructuras existentes, y con los desafíos de la humanidad para buscar soluciones a las situaciones sociales, políticas y económicas, relacionadas con la dignidad humana, de manera que se cree un sano grado de tensión entre las realidades temporales que encontramos y el ideal del Evangelio.

Así, se hace necesario también repensar la noción del bien general, ya que la DSI no es un corpus rígido, sino un mensaje siempre actual y que ha sido elaborado para responder a los distintos contextos y desafíos que la realidad ha ido presentando y a los cuales se responde. El teólogo moral, orientado hacia la teología social, debe resignificar siempre las nociones del pensamiento social contenido en la tradición de la Iglesia, planteando nuevas realidades, escenarios, posibilidades, continuando y aceptando el desafío de la misión de Jesús de ser sal y luz del mundo. En palabras de Francisco (2014):

Este sistema ya no se aguanta. Tenemos que cambiarlo, tenemos que volver a llevar la dignidad humana al centro y que sobre ese pilar se construyan las estructuras sociales alternativas que necesitamos. Hay que hacerlo con coraje, pero también con inteligencia. Con tenacidad, pero sin fanatismo. Con pasión, pero sin violencia. $Y$ entre todos, enfrentando los conflictos sin quedar atrapados en ellos, buscando siempre resolver las tensiones para alcanzar un plano superior de unidad, de paz y de justicia. Los cristianos tenemos algo muy lindo, una guía de acción, un programa, podríamos decir, revolucionario.

\section{Referencias}

Barbieri, W. (2001). Beyond the nations: The expansion of the common good in catholic social thought. Review of Politics, 63(4), 723-754. Doi: https://doi.org/10.1017/ S0034670500032149. 
Benedicto XVI. (2008). Encuentro con los Miembros de la Asamblea General de las Naciones Unidas. Recuperado de http://www.vatican.va/holy_father/benedict_xvi/ speeches/2008/april/documents/hf_ben-xvi_spe_20080418_un-visit_sp.html

Benedicto XVI. (2009). Caritas in veritate. Recuperado de http://w2.vatican.va/content/ benedict-xvi/es/encyclicals/documents/hf_ben-xvi_enc_20090629_caritas-in-veritate.html

Cahill, L. S. (2002). Toward global ethics. Theological Studies, 63(2), 324-344. Doi: https://doi.org/10.1177/004056390206300205.

Carroll, D. (2002). The power of the future in the present: Eschatology and ethics in O'Donovan and Beyond. En C. G. Bartholomew, J. Chaplin \& R. Song (Eds.), A royal priesthood? The use of the Bible ethically and politically: A dialogue with Oliver O'Donovan (pp. 116-143). Grand Rapids, EE. UU.: Zondervan.

Concilio Vaticano II. (1965). Gaudium et spes. Recuperado de http://www.vatican.va/archive/hist_councils/ii_vatican_council/documents/vat-ii_const_19 651207_gaudium-et-spes_sp.html

Congregación para la Doctrina de la Fe. (1986). Libertatis conscientia. Recuperado de http://www.vatican.va/roman_curia/congregations/cfaith/documents/ rc_con_cfaith_doc_19860322_freedom-liberation_sp.html

Coughlin, J. J. (2001). The practical impact of the common good in catholic social thought. St. John's Law Review, 75, 293-296.

Daloz Parks, S., Parks Daloz, L. A., Keen, C. H. \& Keen, J. P. (1996). Commonfire: Leading lives of commitment in a complex world. Boston, Estados Unidos: Beacon Press.

Elsbernd, M. (2005). Social ethics. Theological Studies, 66(1), 137-158. Doi: https://doi. org/10.1177/004056390506600107

Fox, T. C. (2009). Economy for the common good. National Catholic Reporter, 45(17). Doi: https://doi.org/10.3326/pse.42.2.12

Francisco. (2013a). Evangelii gaudium. Recuperado de http://w2.vatican.va/content/ francesco/es/apost_exhortations/documents/papa-francesco_esortazioneap_20131124_evangelii-gaudium.html

Francisco. (2013b). Audiencia General. Recuperado de http://w2.vatican.va/content/ francesco/it/audiences/2013/documents/papa-francesco_20130605_udienza-generale.html

Francisco. (2013c). XXVIII Jornada Mundial de la Juventud. Recuperado de http:// w2.vatican.va/content/francesco/es/travels/2013/outside/documents/papa-francesco-gmg-rio-de-janeiro-2013.html

Francisco. (2014). Discurso del santo padre Francisco a los participantes en el Encuentro Mundial de Movimientos Populares. Recuperado de w2.vatican.va/content/francesco/es/speeches/2014/october/documents/papa-francesco_20141028_incontromondiale-movimenti-popolari.html 
Francisco. (2015a). Laudato si'. Recuperado de http://w2.vatican. va/content/francesco/ es/encyclicals/documents/papa-francesco_20150524_enciclica-laudato-si.html

Francisco. (2015b). Participación en el II Encuentro Mundial de los Movimientos Populares: discurso del santo padre. Recuperado de http://w2.vatican.va/content/francesco/ es/speeches/2015/july/documents/papa-francesco_20150709_bolivia-movimentipopolari.html

Francisco. (2016, noviembre 5). Los Movimientos Populares encuentran a papa Francisco. Recuperado de http://movimientospopulares.org/en-vivo -los-movimientos-populares-encuentran-a-papa-francisco/

Habermas, J. (2006). Entre naturalismo y religión. Madrid, España: Paidós.

Hittinger, R. (2008). The coherence of the four basic principles of catholic social doctrine: An interpretation. En M. S. Archer \& P. Donati (Eds.), Pursuing the common good: How solidarity and subsidiarity can work together (pp. 791-838). Ciudad del Vaticano: Pontificia Academia de Ciencias Sociales.

Hollenbach, D. (2002). The common good and christian ethic: New studies in christian ethics. Nueva York, EE. UU.: Cambridge University Press. Doi: https://doi.org/10.1017/ CBO9780511606380

Juan Pablo II. (1979). Redemptor hominis. Recuperado de http://www.vatican.va/holy_father/john_paul_ii/encyclicals/documents/hf_jp-ii_enc _04031979_redemptor-hominis_sp.html

Juan Pablo II. (1991). Centesimus annus. Recuperado de http://w2.vatican. va/content/ john-paul-ii/es/encyclicals/documents/hf_jp-ii_enc_01051991_centesimus-annus.html

Juan Pablo II. (1996). Christifideles laici. Recuperado de http://www.vatican.va/holy_father/john_paul_ii/apost_exhortations/documents/hf_jp -ii_exh_30121988_christifideles-laici_sp.html

JuanXXIII.(1961).Materetmagistra.Recuperadodehttp://www.vatican.va/holy_father/ john_xxiii/encyclicals/documents/hf_j-xxiii_enc_15051961_mater_sp.html

Juan XXIII. (1963). Pacem in terris. Recuperado de http://www.vatican.va/holy_father/ john_xxiii/encyclicals/documents/hf_j-xxiii_enc_11041963_pacem_sp.html

Maina, W. M. (2011). The common good and/or the human rights: Analysis of some papal social encyclicals and their contemporary relevance. Journal for the Study of Religions and Ideologies, 10(29), 3-25.

Morse, S. \& McNamara, N. (2009). The universal common good: Faith-based partnerships and sustainable development. Sustainable Development, 17(1), 30-48. Doi: https://doi.org/10.1002/sd.368

Novoa, C. (2017, agosto 20). ¿Por qué algunos rechazan al papa Francisco? Razón Pública. Recuperado de https://www.razonpublica.com/index.php/economia-ysociedad/10478-por-qu\%C3\%A9-algunos-rechazan-al-papa-francisco.html 
Pablo VI. (1971). Octogesima adveniens. Recuperado de http://www.vatican.va/ holy_father/paul_vi/apost_letters/documents/hf_p-vi_apl_19710514_octo gesima-adveniens_sp.html

Pablo VI. (1967). Populorum progression. Recuperado de http://www.vatican.va/ holy_father/paul_vi/encyclicals/documents/hf_p-vi_enc_26031967_populorum _sp.html

Parks, D., Laurent, K. \& Keen, J. (2002). Common fire: Leading lives of commitment in a complex world. Boston: Beacon Press.

Pontificio Consejo "Justicia y Paz". (1967). Compendio de la Doctrina Social de la Iglesia. Recuperado de http://www.vatican.va/roman_curia/pontifical_councils/justpeace/ documents/rc_pc_justpeace_doc_20060526_compendio-dott-soc_sp.html

United States Catholic Bishops. (1986). Economic Justice for All: Pastoral Letter on Catholic Social Teaching and the U.S. Economy. Recuperado de http://www.usccb.org/ upload/economic_justice_for_all.pdf

Zanotti, G. (1985). Economía de mercado y Doctrina Social de la Iglesia. Buenos Aires, Argentina: Editorial de Belgrano. 